\title{
Relationship between Platelet Aggregation and the Condition of GPIIb-IIIa Complex in Unstimulated Platelets
}

\author{
Shosaku Nomura, Hirokazu Nagata, Mutsumasa Yanabu, \\ Masahiko Suzuki, Tetsuji Soga, Shigetoshi Ohga, \\ Koji Kondo, Naoaki Sone, Chikaho Kitada, \\ Hiroyuki Kitajima, Terutoshi Kokawa and Kojiro Yasunaga \\ The First Department of Internal Medicine, Kansai Medical University, \\ Moriguchi, Osaka 570, Japan
}

(Received for publication September 5, 1988)

Key words : Platelet aggregation, Glycoprotein II b-IIIa complex, Flow cytometry, Glanzmann's thrombasthenia, Monoclonal antibody

\begin{abstract}
Summary
We used a monoclonal antibody against GP II b- II a complex (NNKY1-32) to study the relationship between platelet aggregation and the condition of GP I b- II a complex in unstimulated platelets. The quantities of GP II b- II a complex in Glanzmann's thrombasthenia (Type I, Type II), Heterozygote, EDTA-treated and cation-treated platelets were classified into three groups according to the binding of anti-GP II b- $\mathbb{I}$ a complex antibody. Despite the similarity in binding of monoclonal anti-GP II b- II a complex antibody within each groups, however, differences were found in platelet aggregability between samples. $\mathrm{Ca}^{2+}$ and $\mathrm{Mg}^{2+}$ promoted the reassociation of dissociated GP II $b$ and GP III $a$ in intact cells, and restored aggregabilities of platelets. In particular, mixed materials $\left(\mathrm{Ca}^{2+}+\mathrm{Mg}^{2+}+\right.$ auto-plasma) significantly restored ADP-induced aggregabilities of platelets. These results suggest the following. The conformational change of GP II b/II a after platelet activation also depends on the conditions of complex formation by GP I $\mathrm{b}$ and GP II $\mathrm{a}$ and the microenvironment around GP II $\mathrm{b} / \mathbb{I I} \mathrm{a}$ in resting platelets. Complex formation alone is insufficient for ADP-induced aggregation, and the presence of $\mathrm{Ca}^{2+}, \mathrm{Mg}^{2+}$ and some factors in plsma appears to be necessary condition.
\end{abstract}

\section{Introduction}

Platelet GP II b and GP II a are said to be major constituents of the plaelet membrane that are critically involved in the formation of the cell surface fibrinogen receptor on activated platelets $^{1},{ }^{2)}$. More recently, it has been reported that the GP II b and GP III a exist predominantly 
$\mathrm{S}-34$

as the $\mathrm{Ca}^{2+}$-dependent, heterodimer complex, and incubation of intact platelets with ethylenediamine tetraacetic acid (EDTA) at $37^{\circ} \mathrm{C}$ causes progressive dissociation of $\mathrm{GP} \mathrm{II} \mathrm{b-} \mathrm{Il} \mathrm{a} \mathrm{com-}$ plexes $^{3-5)}$. The binding of GP I b/ II a to fibrinogen becomes apparent only after stimulation of platelets with an agonist such as ADP or thrombin ${ }^{6,7)}$. Agonists may induce a conformational change directly within GP $\mathbb{I} b / \mathbb{I}$ a so as to render it a competent receptor, or cause changes in the microenvironment so that a hidden receptor becomes accessible to macromolecular ligands 8 , 9). The conformational change of GP II b/III $a$ in stimulated platelets appears thus to be influenced not only by the quantity of GP II b- II a complexes on the unstimulated platelets but also by the associated condition of the "complex" and its microenvironment. In this study, we investigated the relationship between platelet aggregability and GP I b- II a complex in the platelets with various GP I b- I a complexes quantitatively and qualitatively using flow cytometry 10,11).

\section{Materials and Methods}

Monoclonal antibodies : Monoclonal anti-GP II b- II a complex antibody (NNKY1-32) was used. This antibody was described previously $4,5,11-13)$.

Glanzmann's thrombasthenia (GT ${ }^{14,15)}$ and Heterozygote : Type I GT ; 39-year-old woman. Platelet count was normal, bleeding time prolonged, and clot retraction abnormal. Platelet aggregation induced by ADP, collagen, epinephrine and thrombin were defective or declined extremely. Type II GT ; 44-year-old woman. Platelet count was normal, bleeding time prolonged, but clot retraction normal. Platelet aggregation was the same as Type I GT. Heterozygote ; 33-year-old woman, younger sister of the Type I GT patient. Platelet count, bleeding time and platelet aggregation were almost normal.

Incubation of intact platelets with EDTA : Washed platelets were resuspended to a platelet count of $3 \times 10^{8} / \mathrm{m} \ell$, and incubated with EDTA-phosphate buffered saline (PBS) (-) (containing $2 \mathrm{mM}$ EDTA) for 5 to $30 \mathrm{~min}$ at $37^{\circ} \mathrm{C}$. Platelets were washed by centrifugation and treated in $1 \%$ paraformaldehyde (PFA).

Preparation of cation-treated platelets : Washed platelets were incubated with EDTA at $37^{\circ} \mathrm{C}$ for $10 \mathrm{~min}$, washed by centrifugation and resuspended in Tyrode's buffer modified to give a final concentration of $0.1 \mathrm{mM}$ EDTA and $2 \mathrm{mM}$ cation $\left(\mathrm{Ca}^{2+}\right.$ or $\left.\mathrm{Mg}^{2+}\right)$. Platelets resuspended in modified Tyrode's buffer were incubated for $60 \mathrm{~min}$ at $37^{\circ} \mathrm{C}$. In order to investigate the effect of auto-plasma for GP II b- II a complex, EDTA-treated $\left(2 \mathrm{mM}, 37^{\circ} \mathrm{C}, 10 \mathrm{~min}\right)$ platelets were incubated with $\mathrm{Ca}^{2+}(2 \mathrm{mM})$ and $\mathrm{Mg}^{2+}(2 \mathrm{mM})$ for $60 \mathrm{~min}$ at $37^{\circ} \mathrm{C}$, then incubated with auto-plasma for $30 \mathrm{~min}$ at $37^{\circ} \mathrm{C}$. After incubation, platelets were washed by centrifugation and treated with $1 \%$ PFA. 
Fluorescence flow cytometry: Details have been published previously ${ }^{4}, 5,11$. In brief, PFA-treated platelets were incubated with monoclonal antibody $10 \mu \mathrm{g} / m \ell$ for $30 \mathrm{~min}$ at room temperature, then washed 3 times by centrifugation ( $1400 \mathrm{~g}$ for $10 \mathrm{~min}$ at room temperature) and resuspended in the same buffer. The treated platelets were incubated with the fluoresceinlabeled goat anti-mouse antibody (Kirkegard \& Perry Laboratories, Inc., U.S. A.) for $30 \mathrm{~min}$ at room temperature, washed 3 times by centrifugation. The labeled platelets were analyzed on a FACS analyzer (Becton Dickinson \& Co., U.S. A.). Instrument settings were as follows : volume gates were set at channel 10 and 255, FL1 markers were set at channel 0 and 255 . One negative control (autofluorescence), for which unstained platelets were used, was set at 0 and 50. The fluorescence-positive rate was calculated from the total platelet count above channel 51. Another negative control, for which platelets were incubated with fluorescein-labeled goat anti-mouse antibody, was set at the condition that the fluorescence-positive rate is infinitely close to $1 \%$. To quantify fluorescence, SIGMA was defined as

SIGMA $=[$ Mean channel of positive region $\times$ total platelet counts of positive region] $] / 10^{3}$ The change of binding percentage of monoclonal antibodies was expressed as the S.R. (RATIO to SIGMA of normal control). 10,000 events were analyzed in the one-parameter mode. For the two-parameter mode analysis, volume was set at Gate 1 and FL1 was Gate 2. 3,000 events were analyzed in the two-parameter mode.

Change of platelet aggregation: An aggregometer (NKK HEMATRACER 1, Niko Bioscience, Japan) was used for aggregation studies. Platelet samples (Control, GT, Heterozygote, EDTAtreated or cation-treated) were washed with $\operatorname{EDTA}-\operatorname{PBS}(-)$, then preincubated with Tyrode's buffer containing $0.2 \mathrm{mM} \mathrm{CaCl} 2+400 \mu \mathrm{g} / \mathrm{m \ell}$ fibrinogen before the addition of platelet aggregating agent. Final concentrations of platelet agonists were : ADP (Sigma Chemical Co., U.S. A.) $10 \mu \mathrm{M}$; thrombin (Sigma), $0.5 \mathrm{U} / \mathrm{ml}$.

\section{Results}

Reaction of monoclonal anti-human platelet antibodies with GT platelets : Fig. 1 shows twoparameter mode histograms obtained for platelets from a healthy adult, patients with GT (Type I and Tye II) and Heterozygote with NNKY1-32 (anti-GP I b-II a complex). In comparison with the healthy control, Type I GT showed a marked decline in fluorescence intensity, indicating the quantitative absence of GP II b/ II a ; but in Type II GT and Heterozygote, slight or considerable binding of monoclonal antibody was found, suggesting that GP I b and GP I a are partially present.

Dissociation and reassociation of GP II $b$ - II a complexes: The S. R. of NNKY1-32 bound to platelets after incubation for $5,10,15$, and $30 \mathrm{~min}$ at $37^{\circ} \mathrm{C}$ in the presence of $2 \mathrm{mM}$ EDTA 

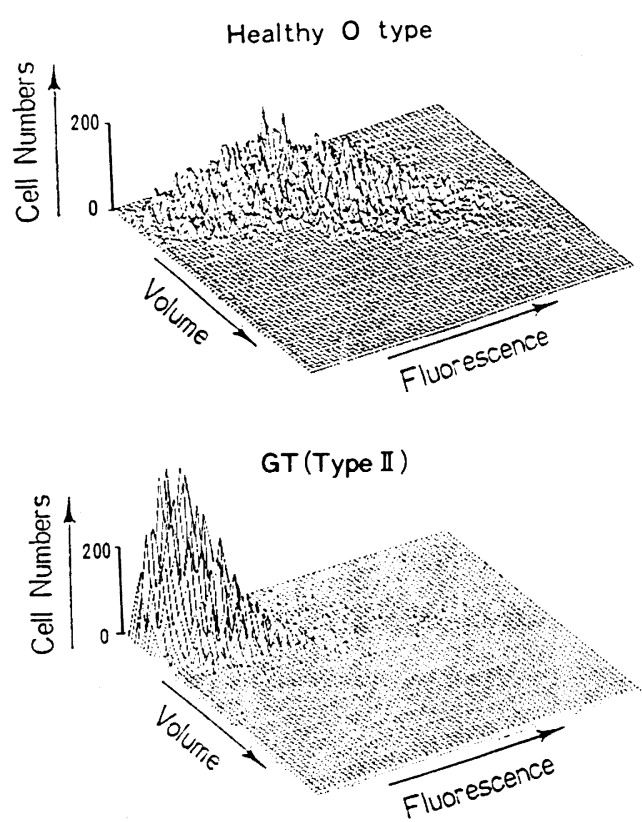

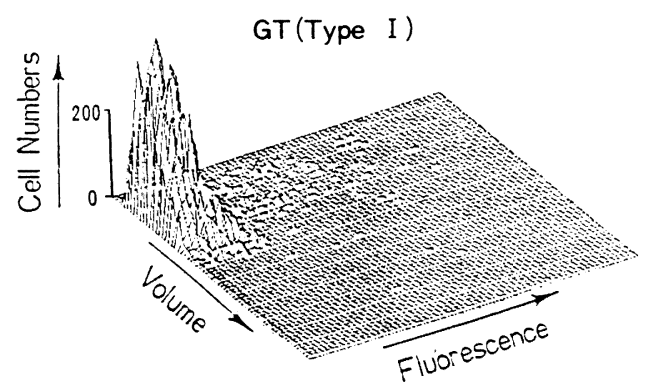

Heterozygote

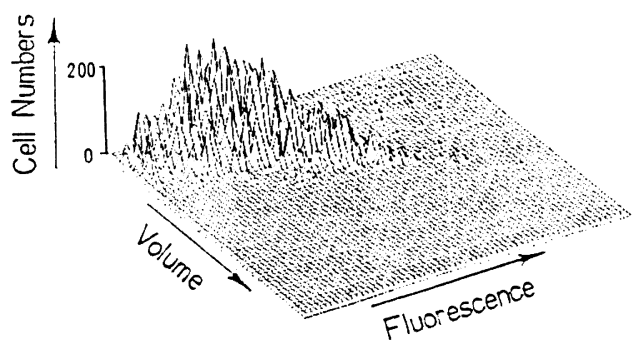

Fig. 1 The two-parameter mode histogram of GT and Heterozygote platelets using monoclonal anti-GP II b-IIIa complex antibody (NNKY1-32).

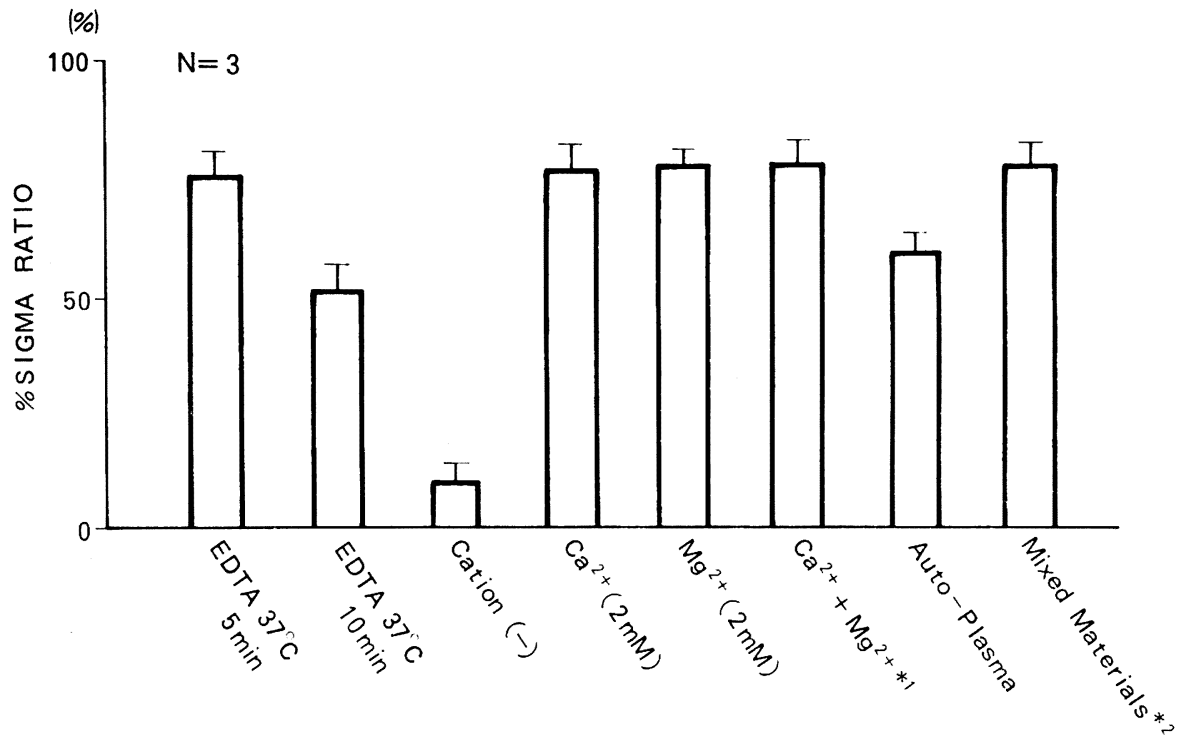

Fig. 2 Dissociation of GP II b-III a complex by EDTA treatment and the effect of cations on the reassociation of GPII b-IIIa complex using NNKY1-32. The change of binding percentage of NNKY1-32 is expressed as the SIGMA RATIO. Results shown are the mean $\pm \mathrm{SD}$ of three experiments. $* 1$ EDTA-treated platelets $\left(2 \mathrm{mM}, 37^{\circ} \mathrm{C}, 10 \mathrm{~min}\right)$ were incubated with $\mathrm{Ca}^{2+}$ and $\mathrm{Mg}^{2+}$ for $90 \mathrm{~min}$ at $37^{\circ} \mathrm{C}$. ${ }^{* 2}$ EDTA-treated platelets were incubated with $\mathrm{Ca}^{2+}$ and $\mathrm{Mg}^{2+}$ for $60 \mathrm{~min}$ at $37^{\circ} \mathrm{C}$, then incubated with autoplasma for $30 \mathrm{~min}$ at $37^{\circ} \mathrm{C}$. 
was reduced remarkably and progressively, as reported previously ${ }^{4,5)}$. In the experiment on the reassociation of GP II b- II a complex after EDTA treatment, treated platelets incubated with cation-free Tyrode's buffer showed progressive dissociation of GP II b- II a complex, while those incubated with the Tyrode's buffer containing $\mathrm{Ca}^{2+}$ or $\mathrm{Mg}^{2+}$ showed reassociation of GP II b- III a complex, as reported previously ${ }^{16)}$. Fig. 2 shows the changes of GP II b- II a complex on EDTA or cation treatment in terms of the S. R. of NNKY1-32.

Change of platelet aggregation : Samples were classified into three groups by the fluorescence

Table 1 Platelet aggregation in GT, Heterozygote, EDTA-treated and cation-treated platelets.

\begin{tabular}{|c|c|c|}
\hline \multirow[b]{2}{*}{ Samples } & \multicolumn{2}{|c|}{ Platelet Aggregation $1 \%$} \\
\hline & ADP & Thrombin \\
\hline I. Type I GT & 0 & 9 \\
\hline Type II GT & 0 & 12 \\
\hline Cation free*1 & 0 & $20 \pm 2$ \\
\hline II. EDTA $37^{\circ} \mathrm{C} 10 \mathrm{~min}$ & 0 & $68 \pm 2$ \\
\hline Auto-Plasma*2 & $8 \pm 3$ & $71 \pm 3$ \\
\hline III. Heterozygote & 95 & 98 \\
\hline EDTA $37{ }^{\circ} \mathrm{C} 5 \mathrm{~min}$ & $31 \pm 2$ & $78 \pm 4$ \\
\hline $\mathrm{Ca}^{2+}(2 \mathrm{mM})^{* 3}$ & $45 \pm 3$ & $72 \pm 3$ \\
\hline $\mathrm{Mg}^{2+}(2 \mathrm{mM})^{* 3}$ & $48 \pm 3$ & $76 \pm 2$ \\
\hline $\mathrm{Ca}^{2+}+\mathrm{Mg}^{2+} * 4$ & $47 \pm 4$ & $77 \pm 3$ \\
\hline Mixed Materials ${ }^{* 5}$ & $70 \pm 2$ & $85 \pm 4$ \\
\hline
\end{tabular}

Platelet aggregation is expressed as the ratio (mean $\pm \mathrm{SD}$ ) of the maximum aggregation of the sample platelets to that of the control platelets. $*_{1}$ : EDTA-treated platelets $\left(2 \mathrm{mM}, 37^{\circ} \mathrm{C}, 10 \mathrm{~min}\right.$ ) were incubated with cation-free Tyrode's buffer for $60 \mathrm{~min}$ at $37^{\circ} \mathrm{C}$. *2: EDTA-treated platelets were incubated with auto-plasma for $60 \mathrm{~min}$ at $37^{\circ} \mathrm{C}$. *3 : EDTA-treated platelets were incubated with cation plus Tyrode's buffer for $60 \mathrm{~min}$ at $37^{\circ} \mathrm{C}$. $* 4:$ EDTA-treated platelets were incubated with $\mathrm{Ca}^{2+}$ and $\mathrm{Mg}^{2+}$ for $90 \mathrm{~min}$ at $37^{\circ} \mathrm{C}$. $* 5$ : EDTA-treated platelets were incubated with $\mathrm{Ca}^{2+}$ and $\mathrm{Mg}^{2+}$ for $60 \mathrm{~min}$ at $37^{\circ} \mathrm{C}$, then incubated with auto-plasma for $30 \mathrm{~min}$ at $37^{\circ} \mathrm{C}$. Relative quantity of GPII b-III a complex by fluorescence intensity of NNKY1-32 : I $(<15 \%)$, II (50 $60 \%)$, III (80 90\%). Results shown are one experiment with Type I GT, Type II GT and Heterozygote, and are the mean \pm SD of three experiments with the other samples. 
intensity of NNKY1-32, and their aggregabilities are shown in Table 1. ADP- and thrombininduced aggregation were defective or declined markedly in GT (Tyepe I, Type II), but retained in Heterozygote platelets. On the other hand, in intact platelets incubated with EDTA at $37^{\circ} \mathrm{C}, \mathrm{ADP}$-aggregability declined more rapidly than the quantity of $\mathrm{GP} \mathbb{I} \mathrm{b} / \mathbb{I I}$ a complex, while thrombin-aggregability was much better maintained. ADP- and thrombin-induced aggregations were observed in $\mathrm{Ca}^{2+}, \mathrm{Mg}^{2+}$, auto-plasma or mixed materials $\left(\mathrm{Mg}^{2+}+\mathrm{Ca}^{2+}+\right.$ autoplasma) treated platelets. But differences were found in ADP-aggregability among these samples.

\section{Discussion}

Platelet GP I b and GP II a are major constituents of the platelet membrane, and autoantibodies against GP II b/II $a$ are recently found in patients with chronic ITP $\left.{ }^{13}, 17,18\right)$. The fibrinogen receptor, which appears to be composed of GP II b/ II a, is expressed only in activated platelets, so that surface conformational change does appear to be required for the induction of the fibrinogen receptor that mediates platelet-platelet contact interactions ${ }^{19)}$. And, it has been reported that but GP $\mathbb{I} \mathbf{b}$ and GP $\mathbb{I}$ a exist predominantly as the heterodimer complex in unstimulated platelets ${ }^{20}$. On the other hand, it has also been reported the incubation of intact platelets with EDTA at $37^{\circ} \mathrm{C}$ causes progressive dissociation of GP $\mathbb{I} b-\mathbb{I}$ a complexes and leads to the decline or loss of ADP-induced aggregation ${ }^{3-5,20)}$. It appears to that the GP II b- II a complex could be reversibly dissociated by brief incubation at $37^{\circ} \mathrm{C}$ with EDTA and could be reassociated by $\mathrm{Ca}^{2+}$ treatment, while longer time was required for polymerization of $\mathrm{GP} I \mathrm{~b}$ and GPII $a^{3,5,20)}$. Moreover, GP I b is the subunit of the complex that binds $\mathrm{Ca}^{2+}$, and putative $\mathrm{Ca}^{2+}$-binding sequences have been identified in GP $\mathbb{I} b^{21,22)}$. In this study, we investigated the relationship between platelet aggregation and the quantity of GP II b- II a complex in GT, EDTA-treated and cation-treated platelets.

The various unstimulated platelets were classified into three groups by the fluorescence intensity of anti-GP I b- $\mathbb{~ a ~ c o m p l e x ~ a n t i b o d y ~ b o u n d ~ t o ~ t h e m ~ a n d ~ i n v e s t i g a t e d ~ t h e i r ~ A D P - ~ a n d ~ t h r o m b i n - ~}$ induced aggregation. When washed platelets were incubated with EDTA at $37^{\circ} \mathrm{C}$ for $10 \mathrm{~min}$ and with cation free Tyrode's buffer at $37^{\circ} \mathrm{C}$ for $60 \mathrm{~min}$, the fluorescence intensity of anti-GP I b- II a complex antibody decreased to about $10 \%$ of that of control platelets. In these platelets the quantities of GP IIb and GP II a were normal, while the quantity of "complex" was markedly decreased, as in Type I and Type II GT. These platelets, classified as group I, underwent the slight thrombin-induced aggregation but did not undergo ADP-induced aggregation. It was speculated that the quantity of GP I b- II a complex in the unstimulated platelets was below the level needed for fibrinogen-mediated aggregation to be induced when platelets are stimulated. 
When EDTA-treated platelets were incubated with auto-plasma, the fluorescence intensity of anti-GP II b- II a complex antibody was about $60 \%$ of that of control platelets, about the same as that of platelets incubated with EDTA at $37^{\circ} \mathrm{C}$ for $10 \mathrm{~min}$. This is the interesting result. Because it is speculated that the concentration of cations in auto-plasma is insufficient for the reassociation of GP $\mathbb{I} b-\mathbb{I}$ a complex. In the previous ${ }^{5)}$ and this studies, we reported that $\mathrm{Ca}^{2+}(2 \mathrm{mM})$ and $\mathrm{Mg}^{2+}(2 \mathrm{mM})$ promoted the reassociation of dissociated $\mathrm{GP} \mathbb{I} \mathrm{b}$ and GP II $\mathbf{a}$ in intact cells. Moreover, recently, we confirmed the reassociation of GP II b- II a complex by cation using immunoelectron microscopy ${ }^{16)}$. It appears to need the same concentration of cations as in vivo to promote the reassociation of GP II b- III a complex.

When EDTA-treated platelets were incubated with Tyrode's buffer containing $\mathrm{Ca}^{2+}, \mathrm{Mg}^{2+}$ or mixed materials $\left(\mathrm{Ca}^{2+}+\mathrm{Mg}^{2+}+\right.$ auto-plasma), the fluorescence intensity of anti-GP $\mathbb{I} b-\mathbb{I} \mathbf{a}$ complex antibody was about $80 \%$ that of control platelets. This quantity of GP II b- II a complex was almost as same as that of platelets incubated with EDTA at $37^{\circ} \mathrm{C}$ for $5 \mathrm{~min}$ and of the Heterozygote platelets which used this study. ADP- and thrombin-induced aggregation was observed under these conditions, the latter stronger than the former. Differences in both aggregabilities were also observed between samples (EDTA treatment, cation treatment and Heterozygote). Particularly, there existed the marked discrepancy in ADP-induced aggregation. ADP-aggregability of $\mathrm{Ca}^{2+}$ or $\mathrm{Mg}^{2+}$ treated platelets was stronger than that of platelets incubated with EDTA at $37^{\circ} \mathrm{C}$ for $5 \mathrm{~min}$. And ADP-aggregability of the mixed materials treated platelets and the Heterozygote platelets were stronger than that of $\mathrm{Ca}^{2+}$ or $\mathrm{Mg}^{2+}$ treated platelets. This result explains the "quantitative" as well as "qualitative" importance of GP II b$\mathbb{I I}$ a complex in unstimulated platelets. It was speculated that these quantities of GP II b- II a complexes could be aggregated by ADP, but that if GP II b and GP III a were merely associated, the conformational change of GP II b/ II a was difficult of induction by ADP. Perhaps it is important that quality of GP II b- $\mathbb{I}$ a complex, the microenvironment around "complex" or some factor in plasma.

In this study, the discrepancy was observed between thrombin-induced aggregation and the quantity of GP II b- II a complex in unstimulated platelets. It has been reported that fibrinogen, von Willebrand factor (vWF), fibronectin and thrombospondin (TSP), which are members of a platelet-adhesive protein family including Arg-Gly-Asp (RGD) peptide ${ }^{23)}$, associated with activated platelets, and that the three adhesive proteins other than TSP can directly bind to or near the GP II b- II a complex when platelets are stimulated with thrombin ${ }^{24)}$. Moreover, recently, it is reported that the quantity of GP II b- II a complex increased in the expression of GP II b/ II a-related epitopes on the platelet surface following activation with strong agonists ${ }^{25}$, 26). It may be that thrombin-induced aggregation involves aggregating mechanisms different 
from ADP-induced aggregation ${ }^{27)}$.

The qualitative importance of GP II $\mathrm{b}-\mathbb{I I}$ a complex has been reported previously. A variant of $\mathrm{GT}^{28)}$, acquired $\mathrm{GT}^{29)}$ and functional $\mathrm{GT}^{30}$ ) appeared to be caused by abnormality of GP II b/ II a itself, autoanti-platelet antibody and drug metabolites, respectively. In all these cases, GP II b- II a complex was normal quantitatively. Therefore, it is speculated that both quantitative and qualitative factors concerning the GP II b- II a complex of unstimulated platelets are important for the conformational change of GP II $b / \mathbb{I} a$ in the activated platelets by ADP.

\section{References}

1) Nachman, R. L. and Leung, L. L. K. : Complex formation of platelet membrane glycoprotein II b and IIIa with fibrinogen. J. Clin. Invest., 69, 263 269, 1982.

2) Bennet, J. S., Hoxie, J, A., Leitmann, S. F., Vilaire, G. and Cines, D. B. : Inhibition of fibrinogen binding to stimulated human platelets by a monoclonal antibody. Proc. Natl. Acad. Sci. USA., 80, 2417 2421, 1983.

3 ) Pidard, D., Didry, D., Kunicki, T. J. and Nurden, A. T. : Temperature-dependent effects of EDTA on the membrane glycoprotein II b-IIIa complex and platelet aggregability. Blood, 67, 604 611, 1986.

4) Nomura, S., Nagata, H., Kitajima, H., Sone, N., Hirai, K., Oda, K., Kokawa, T. and Yasunaga, K. : Analysis of platelet membrane GP II b-IIIa using flow cytometry. Blood \& Vessel, 18, 127 130, 1987.

5 ) Nomura, S., Nagata, H., Oda, K., Kokawa, T. and Yasunaga, K. : Effects of EDTA on the membrane

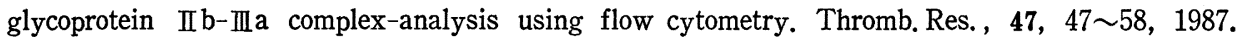

6) Musturd, J. F., Packham, M. A., Kinlough-Rathbone, R. L., Perry, D. W. and Regoeczi, E. : Fibrinogen and ADP-induced platelet aggregation. Blood, 52, 453〜466, 1978.

7 ) Hawiger, J., Parkinson, S. and Timmons, S. : Prostacyclin inhibits mobilization of fibrinogen-binding sites on human ADP- and thrombin-tretaed platelets. Nature, 283, 195 197, 1980.

8 ) Shattil, S. J., Hoxie, J. A., Cunningham, M. and Brass, L. F. : Changes in the platelet membrane glycoprotein II b-IIIa complex during platelet activation. J. Biol.Chem., 260, 11107 11114, 1985.

9) Coller, B. S. : Activation affects access to the platelet receptor for adhesive glycoproteins. J. Cell. Biol., 103, 451 456, 1986.

10) Herzenberg, L. A. and Sweet, R. G. : Fluorescence-activated cell sorting. Sci. Am., 234, 108 117, 1976.

11) Nomura, S., Nagata, H., Sone, N., Oda, K., Kokawa, T. and Yasunaga, K. : Analysis of platelet surface antigens using flow cytometry-fundamental study and significance-. Clin. Immunol., 19, 717 724, 1987.

12) Nagata, H., Nomura, S., Oda, K., Kokawa, T. and Yasunaga, K. : Analysis of the functional role of platelet membrane glycoproteins with monoclonal antibodies. (abstr.) Thromb. Haemostas., 58, 192, 1987.

13) Nomura, S., Nagata, H., Sone, N., Oda, K., Kokawa, T. and Yasunaga, K. : Analysis of platelet antigens for anti-platelet antibodies in ITP using flow cytometry. (abstr.) Thromb. Haemostas., 58, 481, 1987.

14) Yasunaga, K. : Congenital platelet function disorders; Survey and pathophysiology. Acta. Haematol. Jpn. , 49, 1499 1508, 1986.

15) Nomura, S., Nagata, H., Kitada, C., Sone, N., Oda, K., Kokawa, T., Yasunaga, K., Nakajima, T. and Endo, K. : Analysis of Glanzmann's thrombasthenia and Bernard-Soulier syndrome using flow 
cytometry. Jpn. J. Clin. Hematol., 28, 377〜385, 1987.

16) Nomura, S., Nagata, H., Kitajima, H., Sone, N., Soga, T., Ohga, S., Kondo, K., Kitada, C., Kokawa, T. and Yasunaga, K. : Role of cations on the platelet membrane GPIlb-IIIa complex. Blood \& Vessel, 19, 236 245, 1988.

17) Nomura, S., Nagata, H., Sone, N., Oda, K., Kokawa, T. and Yasunaga, K. : Analysis of platelet antigen for anti-platelet antibodies in idiopathic thrombocytopenic purpura using flow cytometry. Acta. Haematol. Jpn., 51, 118 129, 1988.

18) McMillan, R., Tani, P., Millard, F., Berchtold, P., Renshow, L. and Wood, V.L. : Plateletassociated and plasma anti-glycoprotein autoantibodies in chronic ITP. Blood, 70, 1040 1045, 1987.

19) Parise, L. V. and Philips, D. R. : Reconstitution of the purified platelet fibrinogen receptor : Fibrinogen binding properties of the glycpprotein II b-III a complex. J. Biol. Chem., 260, 10698 10707, 1985.

20) Fitzgerald, L. A. and Phillips, D. R. : Calcium regulation of the platelet membrane glycoprotein II b-III a complex. J. Biol. Chem., 260, 11366 11374, 1985.

21) Poncz, M., Eisman, R., Heienreich, R., Silver, S. M., Vilaire, G., Survey, S., Schwarts, E. and Bennett, J.S. : Structure of the platelet membrane glycoprotein $\mathbb{I l} \mathrm{b}$ : Homology to the alpha subunits of the vitronectin and fibronectin membrane receptors. J. Biol. Chem., 262, 8476 8482, 1987.

22) Phillips, D. R., Charo, I. F., Parise, L. V. and Fitzgerald, L. A. : The platelet membrane glycoprotein II b-IIIa complex. Blood, 71, 831 843, 1988.

23) Ruoslahti, E. and Pierschbacher, M.D. : New perspectives in cell adhesion : RGD and integrins. Science, 238, 491 497, 1987.

24) Aiken, M. L., Ginsberg, M. H. and Plow, E. F. : Divalent cation-dependent and independent surface expression of thrombospondin on thrombin-stimulated human platelets. Blood, 69, 58 64, 1987.

25) Niiya, K., Hodson, E., Bader, R., Byers-Ward, V., Koziol, J. A., Plow, E. F. and Ruggeri, Z. M. : Increased surface expression of the membrane glycoprotein $\mathbb{I I} \mathrm{b} / \mathrm{III}$ a complex induced by platelet activation. Relationship to the binding of fibrinogen and platelet aggregation. Blood, 70, 475 483, 1987.

26) Nomura, S., Nagata, , H., Sone, N., Kitada, C., Kitajima, H., Oda, K., Kokawa, T. and Yasunaga, K. : Change of platelet surface conformation in ADP- and collagen-induced aggregation. Blood \& Vessel, 19, 260 263, 1988.

27) Nomura, S., Nagata, H., Yanabu, M., Suzuki, M., Soga, T., Ohga, S., Kondo, K., Sone, N., Kitada, C., Kitajima, H., Kokawa, T. and Yasunaga, K. : Analysis of platelet surface conformation in thrombin-induced aggregation (submitted).

28) Nurden, A. T., Rosa, J-P., Fournier, D., Legrand, C., Didly, D., Parquet, A. and Pidard, D. : A variant of Glanzmann's thrombasthenia with abnormal glycoprotein II b-IIIa complex in the platelet membrane. J. Clin. Invest., 79, 962 969, 1987.

29) Niessner, H., Clemetson, K. J., Panzer, S., Mueller-Eckhardt, C., Santoso, S. and Bettelheim, P. : Acquired thrombasthenia due to GPII b/III a specific platelet autoantibodies. Blood, 68, 571 573, 1986.

30) Di Minno, G., Cerbone, A. M., Mattioli, P. L., Turco, S., Iovine, C. and Mancini, M. : Functionally thrombasthenic state in normal platelets following the administration of ticlopidine. J. Clin. Invest. $\mathbf{7 5}$, 328 338, 1985. 